\title{
Participation in Daily Activities among Working Women Following Breast Cancer
}

\author{
Khawla Loubani-Hawaita ${ }^{1,2}$, Naomi Schreuer1, Uzi Milman ${ }^{3,4}$ \\ ${ }^{1}$ Department of Occupational Therapy, Faculty of Social Welfare \& Health Sciences, University of Haifa, \\ Mount Carmel, Haifa, Israel \\ ${ }^{2}$ Department of Occupational Therapy, Clalit Health Services, Haifa and Western Galilee, Israel \\ ${ }^{3}$ Clinical Research Unit, Clalit Health Services, Haifa and Western Galilee District, Haifa, Israel \\ ${ }^{4}$ Department of Family Medicine, Faculty of Medicine, Technion-Israel Institute of Technology, Haifa, Israel \\ Email:khawlaloubani@gmail.com,schreuer@research.haifa.ac.il, UZIMI@clalit.org.il
}

Received 18 June 2016; accepted 2 August 2016; published 5 August 2016

Copyright (C) 2016 by authors and Scientific Research Publishing Inc.

This work is licensed under the Creative Commons Attribution International License (CC BY). http://creativecommons.org/licenses/by/4.0/

(c) (i) Open Access

\begin{abstract}
Introduction: This study aimed to identify the variables explaining retained activity level for working women with breast cancer; the variables correlating with their performance in daily activities they prioritize; and factors facilitating or restricting their return to work. Method: Sixty working women with breast cancer aged 25 - 65 years completed a personal data questionnaire, the modified Activity Card Sort, the Canadian Occupational Performance Measure; and two openended questions about facilitators and barriers to work. Results: Activity levels dropped by a quarter following BC treatments. Most women (67\%) decreased their weekly working hours, although a third identified work as their highest priority. A higher total retained activity level was explained by fewer limitations on the range of motion (upper extremity), age younger than 45 years, and higher educational attainment. Cognitive limitations and limited range of motion negatively correlated with retained activity level at work. Personal and disease factors, job demands, and environmental factors facilitated or restricted return to work. Conclusion: Interventions should focus on physical and cognitive rehabilitation to regain functioning in the context of work and productive daily activities. Special attention should be paid to the greater needs of younger women.
\end{abstract}

\section{Keywords}

Breast Cancer, Participation, Meaningful Daily Activities, Working Women

\section{Introduction}

Women who survive breast cancer (BC) commonly experience a variety of long-term physical and psychologi-

How to cite this paper: Loubani-Hawaita, K., Schreuer, N. and Milman, U. (2016) Participation in Daily Activities among Working Women Following Breast Cancer. Open Journal of Therapy and Rehabilitation, 4, 150-162.

http://dx.doi.org/10.4236/ojtr.2016.43014 
cal symptoms following the disease and its treatment [1]-[5]. Although more and younger women survive worldwide [6], in some cases, the survivors do not fully retain participation in daily activities that were part of their life prior to beginning treatment for BC [7] [8]. Expressed in the terms used by the International Classification of Functioning, Disability and Health (ICF) published by the World Health Organization [9], this means that they experience reduced involvement in life situations that are part of their sociocultural context.

Considerable research effort has been invested in ameliorating the physical and emotional consequences of BC and its treatment, but few studies have examined rehabilitation methods to meet women's non-physical sequelae such as psychosocial, cognitive, occupational, and broader lifestyle performance factors [10]. Problems that affect functioning increasingly spark visits to the general practitioner, even years after the end of treatment. Indeed, 2 - 5 years after diagnosis, BC survivors were found to consult their general practitioner: 18\% more frequently than controls for abdominal pain and fatigue, $55 \%$ more frequently for sleep disturbance, and $64 \%$ more frequently for depression [11].

Few studies have been published on evidence-based rehabilitation interventions that encourage satisfying role resumption and full participation in meaningful daily activities [4]. Occupational therapy (OT) interventions are considered potentially relevant and useful in the rehabilitation and management of the functional limitations associated with BC treatment [12]. Indeed, the parameters for developing an evidence-based OT intervention to promote return to work have only recently been published [13], although it is known that decreased participation, particularly in the labor market, poses a challenge to individuals, families, and society [7]. To overcome the current lack of evidence-based rehabilitation interventions to improve survivor participation, researchers first need reliable information on how BC and its treatments affect survivor's participation and functioning in daily activities and on the rehabilitation goals that are of importance to survivors.

\subsection{Theoretical Framework}

To achieve the broad goal identified above, we have adopted the ICF framework for describing disability and health-related states, following BC diagnosis [9]. The ICF considers functioning as an interaction between a disease, its symptoms related to impaired body structure and function, and personal factors pertaining to the patient. In addition, a client-centered approach was used [14] to assess women's self-perceptions of changes in their performance of meaningful daily activities that they participate in while encountering BC. A clientcentered assessment was chosen in the belief that functional goal setting for women with BC may enhance their return to previous roles, assist them acquire control, and encourage a positive self-concept with respect to daily function [15].

\subsection{Literature Review}

Breast cancer is classified into four stages: in stage I patients have small localized tumors, no discernible metastases, and the best prognosis. Stage II includes larger tumors that involve the axillary lymph nodes, and Stage III involves clearly invasion of tissues around the breast. Stage IV patients may have tumors of any size, with the presence of documented metastases to other tissues or sites; they typically have the poorest prognosis and shorter life expectancy [16]. Following range of surgical interventions and adjuvant therapies (chemotherapy, hormone therapy, immunotherapy, and radiation therapy) [17], women commonly experience long term interacting physical, psychological and cognitive symptoms that limit their involvement in familiar daily activities.

As summarized by [10], the physical symptoms of the disease (BC) and its treatments include pain, fatigue and impaired shoulder function, lymphedema and numbness of the skin of the upper arm. Both long-term postoperative pain and lymphedema affect up to $50 \%$ of women. Affective symptoms include anxiety, depression, emotional distress caused by shifts in social support, and fear of cancer recurrence and death. Cognitive symptoms occur in $10 \%$ - 50\% of women [10]. They include difficulties with attention, short-term memory and executive functioning and may affect functioning at home and at work. Employment-related matters, such as time needed to return to work, work absenteeism, and sick leave or employment status, are a particular concern for women survivors of BC [10].

Young to middle aged women are still in the process of establishing their participation in careers, families and social lives. The cancer diagnosis, treatments and symptoms occur during a period of their lives when there are high demands for peak performance in work and family management and less flexibility in activity scheduling 
[8]. Indeed, challenges in performing activities in work, home, or self-care are most apparent in women under the age of 60 [18].

Employed women consider their return to work a significant aspect of returning to participation [19] [20] and one that helps them to increase feelings of normalcy and distracts them from focusing on their illness [21]. Delayed return to work following treatment for BC influences personal health and well-being, family economy, and social relations at the workplace [21] [22]. Return to work may be affected by numerous barriers and facilitators including factors related to the person (socio-demographic, education), to the disease (poor health and fatigue) and to the workplace (heavy physical work and employer support, flexibility in work demands, peer support). Identifying and then minimizing the barriers and strengthening the facilitators is the recommended path to increasing the back-to-work rate of BC survivors [23]. Understanding work-related issues associated with cancer can provide relevant information regarding potential treatment and psychological support for breast cancer survivors [24].

Occupational therapists as part of the rehabilitation teams are trained to enhance participation and to improve functioning of their clients in work, leisure or activities of daily living that are desired and/or necessary to one's well-being [25] [26]. However, few studies have focused on the various aspects of retaining employment during the detection and treatment of BC through long-term survivorship or on the limitations these impose on participation [4].

The current study sought to contribute toward closing this gap in the literature by developing a client centered understanding of the variables affecting participation by women with $\mathrm{BC}$, the activities they prioritize, and the issues they face.

\subsection{Research Objectives}

1) To identify which disease, symptom, and demographic variables explain retained activity level (RAL; i.e., currently-performed activities as a proportion of all activities ever performed, see methods) following treatment for BC.

2) To identify the variables associated with women's performance and satisfaction with their performance in the daily activities they prioritize following treatment for BC.

3) To examine which disease, symptom, and demographic variables correlate with RAL at work (in terms of time until return to work and number of working hours per week) following treatment for BC.

4) To identify factors that facilitated or impeded return to work.

We anticipated that the answers to these questions will be of value to general practitioners treating workingaged BC survivors and that they will guide the development of rehabilitative interventions.

\section{Methods}

\subsection{Design}

The study design is cross-sectional, conducted among women who experienced treatment for BC. It involved a client-centered assessment of women's self-reports of their current levels of participation in preferred daily activities in relation to their recalled participation level, and the symptoms they experience.

\subsection{Participants}

\subsubsection{Eligibility Criteria}

Following the literature [16] and consultation with the oncology expert, inclusion criteria were: women who had a diagnosis of Invasive Ductal Carcinoma cancer stages I to III; were aged 25 - 65 years; had worked up until the BC diagnosis; were at least three months post-surgery; had been previously healthy; and were receiving or had completed medical treatments (chemotherapy, radiotherapy, endocrine therapy), who are expected to return to daily life routine, but often remain with unmet functional needs [27]. Exclusion criteria were the reoccurrence of $\mathrm{BC}$ or the failure to meet any one of the inclusion criteria, in order to utilize the effect of BC, without other accumulated health conditions. The appropriate sample size was calculated using G*Power [28] power of 0.80, $\alpha=0.05)$ and utilized the average (42.8) and standard deviation $( \pm 19.33)$ of the main outcome measure (the modified Activity Card Sort, ACS), obtained from a previous study that used the ACS among people following Stroke [29]. 


\subsubsection{Ethics}

Ethical approval was obtained from the Helsinki Committee of Clalit Health Services.

\subsubsection{Demographic Descriptors of the Sample}

Sixty women were recruited at three ambulatory oncology clinics. Participants responded to a call promoted by the medical and social-work team. Participants' socio-demographic and disease variables are shown in Table 1.

\subsection{Instruments}

\subsubsection{A Personal Data Questionnaire}

This questionnaire (developed specifically for this study) provided the independent variables. The questionnaire collected data across five areas: demographic variables (age, marital status, educational attainment level, monthly income); disease variables (cancer stage, surgical intervention, and time since surgery); medical treatments (chemotherapy, radiotherapy, and endocrine therapy); severity of symptoms (reported on a scale of 1 (low) to 4 (extreme), based on the Functional Assessment of Cancer Therapy (FACT) [30]. The symptoms were divided into: a) physical (fatigue and peripheral neuropathy); b) Specific limitation in range of motion in the upper extremity (LROM) in the affected side; c) cognitive; d) psychological (depression and anxiety). The fifth area covered return-to-work (time until return to workand number of working hours per week).

At the end of the questionnaire, the women were asked two open-ended questions regarding factors that facilitated or impeded their return to work following treatment for BC. The questions cued the women with respect to: 1) personal and disease factors; 2) factors related to job demands; and 3) factors related to the workplace environment (human and physical factors).

\subsubsection{The Activity Card Sort (ACS)}

The ACS [31] was developed as a measure of participation. The current study used the "Recovering Version B" of the modified ACS adapted for Israeli population [32]. The tool that was used in the current study comprises 88 pictures of adults performing a wide range of daily activities, to which we added an additional card for the activity "work". The participant was asked to sort the 89 activities into categories in a two-phase process. In the first phase, the participant was asked to categorize the activities as: "Done before illness" $(=1)$, "New activity since illness" $(=1)$, or "Not done before illness" $(=0)$. In the second phase, the participant was asked to categorize the "Done before illness" group into: "Continued to do during illness" (=1); "Doing less following illness"

Table 1. Socio-demographic and disease characteristics of the participants.

\begin{tabular}{|c|c|c|c|}
\hline Variable & Subgroup & Number $(\mathbf{N}=\mathbf{6 0})$ & Percent \% \\
\hline Age (years) & $\begin{array}{l}\text { Under } 45 \text { years } \\
\text { Over } 45 \text { years }\end{array}$ & $\begin{array}{l}38 \\
22\end{array}$ & $\begin{array}{l}63.3 \\
36.7\end{array}$ \\
\hline Marital status & $\begin{array}{c}\text { Married } \\
\text { Not married }\end{array}$ & $\begin{array}{l}43 \\
17\end{array}$ & $\begin{array}{l}72 \\
28\end{array}$ \\
\hline $\begin{array}{c}\text { Educational } \\
\text { attainment level }\end{array}$ & $\begin{array}{l}\text { Secondary } \\
\text { Tertiary }\end{array}$ & $\begin{array}{l}21 \\
39\end{array}$ & $\begin{array}{l}35 \\
65\end{array}$ \\
\hline Monthly income & $\begin{array}{l}\text { Low } \\
\text { High }\end{array}$ & $\begin{array}{l}36 \\
24\end{array}$ & $\begin{array}{l}60 \\
40\end{array}$ \\
\hline Cancer stage & $\begin{array}{c}\text { I } \\
\text { II } \\
\text { III }\end{array}$ & $\begin{array}{l}19 \\
15 \\
37\end{array}$ & $\begin{array}{c}31.7 \\
25 \\
61.7\end{array}$ \\
\hline Decreased work & $\begin{array}{l}\text { Yes } \\
\text { No }\end{array}$ & $\begin{array}{l}40 \\
20\end{array}$ & $\begin{array}{l}67 \\
33\end{array}$ \\
\hline Back to work after & $\begin{array}{l}\text { Less than } 3 \text { months } \\
3 \text { months to } 1 \text { year } \\
\text { Did not return }\end{array}$ & $\begin{array}{l}32 \\
17 \\
11\end{array}$ & $\begin{array}{l}53.3 \\
28.3 \\
18.4\end{array}$ \\
\hline
\end{tabular}

Age measured in years; "Decreased work" refers to whether the respondent decreased the number of hours she worked each week following treatments; Monthly income indicates monthly income below or above the average income, according to the Israeli Census. 
$(=0.5)$; or "Given up due to illness" $(=0)$. The scores from each phase were summed separately and then the proportion of retained activities was calculated as the sum for Phase 2 (representing the current post-BC-treatment activity level) divided by the sum for Phase 1 (representing all activities ever performed). The resulting fraction is expressed a percentage and termed the Retained Activity Level (RAL). A total RAL score of less than $100 \%$ indicates reduced participation post-compared with pre-BC treatment.

There is a debate in the literature regarding how the ACS activities should be divided with respect to activity type. Researchers who have used the adapted version in our context found five factors: instrumental activities of daily living (IADL) (for example: driving, paying bills, child care); social-cultural activities (for example: traveling, visiting friends); leisure activities with low-physical demands (for example: watching television and reading); and leisure activities with high-physical demands (for example: hiking and sports); they found construct validity upon comparing the activity levels of healthy adults with those of populations with neurological disabilities [33] [34]. The current study revealed a fairly high internal consistency ( $\alpha=0.75)$ for the total RAL score of the modified ACS.

\subsubsection{The Canadian Occupational Performance Measure (COPM)}

The COPM [35] [36] was administered to identify women's priorities following treatment for BC. The COPM is a semi-structured interview that measures self-perceptions of occupational performance in the domains of selfcare (for example dressing, walking, transportation), productivity (for example work, housekeeping, shopping), and leisure (for example reading, sports, socialization). Participants were asked to prioritize in open-ended answers up to five daily activities that they want, need, or are expected to do. These activities are then rated on an ordinal 10-point scale relating to: importance $(1=$ "not important", 10 = very important); performance $(1=$ "not able to do it at all" to 10 = "able to do it extremely well"); and satisfaction with performance ( 1 = "not satisfied at all" and $10=$ "extremely satisfied"). The averages of the performance and total satisfaction scores were then calculated for the preferred activities to provide the performance and satisfaction components of the participation variable for the current study. Test-retest reliability was found to be 0.63 for satisfaction and 0.84 for performance (Law, Baptiste et al., 1994). The construct and criterion validity of the COPM and its usefulness for application to community practice were supported by [36].

A schematic representation of the measures we used and the variables we examined in the context of the ICF [9] can be seen in Figure 1.

\subsection{Procedure}

The sample was selected from three main ambulatory oncological clinics in northern Israel. After receiving the approval of the Helsinki (ethics) Committee of Clalit Health Services, women with Invasive Ductal Carcinoma who were diagnosed and began to receive therapy during the years 2010-2012 were recruited with the help of the medical staff of oncology clinics. The first sixty women who addressed the call and met the inclusion criteria were included in the study. After giving her written consent to participate, each woman met the occupational therapist researcher for about 90 minutes either at her home or at the oncology clinic and completed the questionnaires.

\subsection{Data Analysis}

Data analysis was performed using the Statistical Package for Social Sciences (SPSS) version 19 [37]. Descriptive statistics were used to describe the frequencies, averages, and standard deviations of the variables. Demographic variables were transformed into dummy variables ( 0 or 1$)$ to enable quantitative analyses. Correlations between demographic quantitative variables and disease variables were tested using Pearson's correlations. Associations between symptom severity and RAL were tested using Spearman's correlations. As a result of the significant correlations found with the RAL, a two-step multivariate regression was examined to verify a model of the variables that explained the total RAL. The first step included only the demographic variables and the second step included all the research variables.

Descriptive statistics were collected from the COPM regarding the five activities receiving the highest importance scores (prioritized activities). Correlations between the average scores for performance and satisfaction as assessed by the COPM and the independent demographic and disease variables were examined by Pearson's analyses; and with symptom severity by Spearman's correlations. 


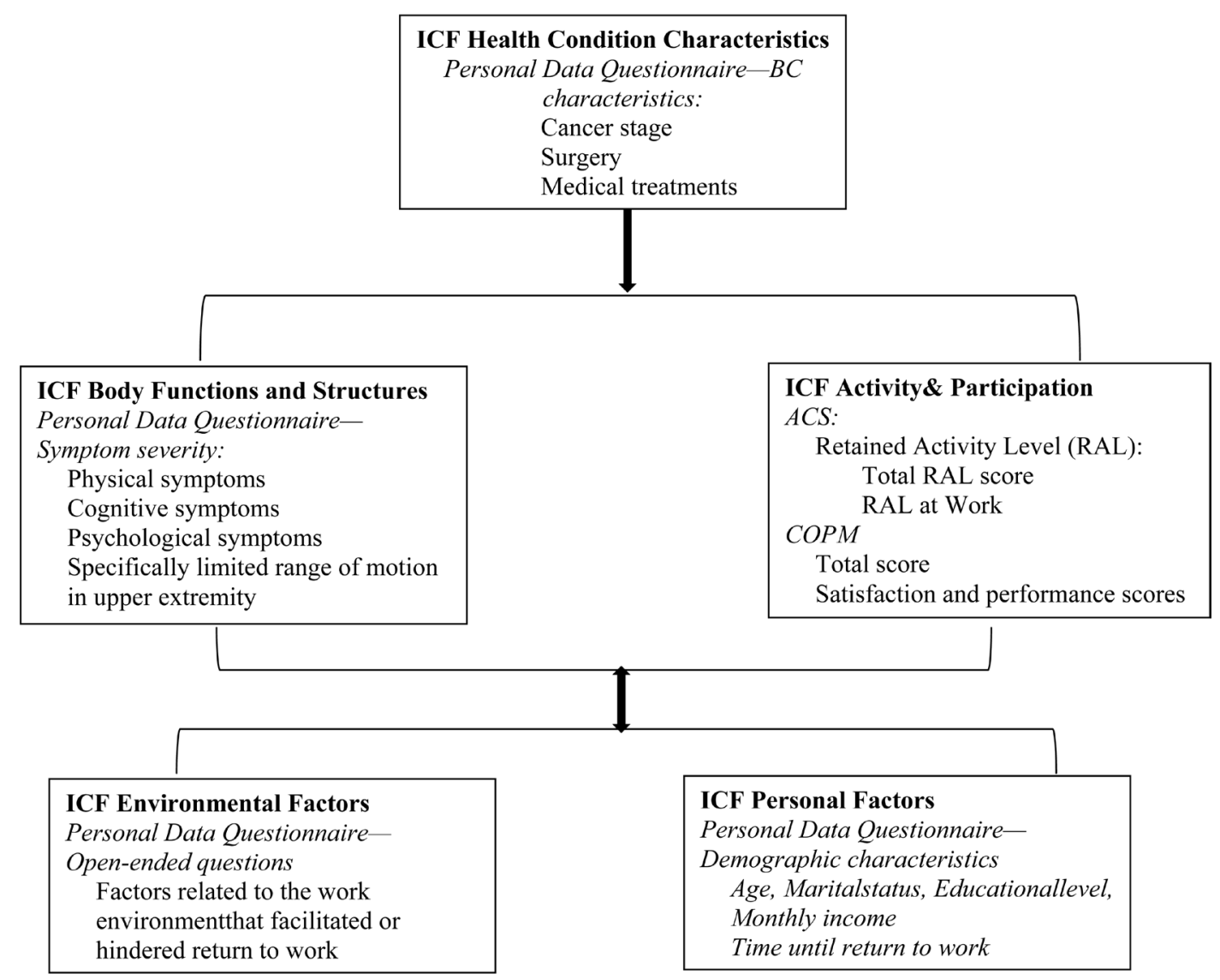

Figure 1. The measures (italicized text) used to assess the categories of variables examined in this study (normal text) are depicted in the context of the taxonomy (bold headings) and relationships (thin interconnecting lines between boxes) of the International Classification of Functioning, Disability, and Health (ICF) [9] for working women with breast cancer (BC). The relationships examined in the current study are indicated by the thicker lines and arrow heads. ACS, Activity Card Sort, specifically, the "Recovering Version B" of the modified ACS adopted for Israeli population; COPM, Canadian Occupational Performance Measure.

The reported factors (from the two open questions) that facilitated and/or impeded women's return to work were sorted into three categories: 1) personal and disease factors; 2) factors related to job demands; and 3) factors related to the human and physical environments at work.

\section{Results}

The mean age of the participants was 47.82 years ( $\mathrm{SD}=8.56$ years). Among the sixty women with BC, nineteen (31.7\%) were diagnosed with BC stage one; 26 (43.4\%) stage two, and 15 (25\%) stage three; 37 (61.7\%) had undergone mastectomy and 23 (38.8\%) had undergone lumpectomy. At the time of the interviews, 44 participants (73\%) were receiving medical treatments and $16(27 \%)$ had completed them. Most women received a combination of two medical treatments (SD = 1); 40 (67\%) women received chemotherapy, 30 (65\%) received radiotherapy and 49 (82\%) received endocrine therapy. Frequencies and percentages of symptoms severity are presented in Table 2.

\subsection{Disease, Symptom, and Demographic Variables That Explain RAL Following BC Treatment}

The total RAL as calculated from the ACS (modified) was 75\%, indicating that, on average, women lost 25\% of their previous activities following BC treatments. Disease, demographic variables and symptoms that correlated with the total RAL are presented in Table 3. As presented in Table 3, none of the disease variables 
Table 2. Frequencies and percentages of symptoms severity.

\begin{tabular}{ccccccccc}
\hline \multirow{2}{*}{$\begin{array}{c}\text { Symptom } \\
\text { Severity } \\
(1-4 \text { scale })\end{array}$} & \multicolumn{2}{c}{ Symptom Type } \\
\cline { 2 - 9 } & Prequency & Percent \% & Frequency & Percent \% & Frequency & Percent \% & Frequency & Percent \% \\
\cline { 2 - 10 } Low (1) & 10 & 16.6 & 32 & 53.3 & 31 & 51.7 & 26 & 43.3 \\
Moderate (2) & 18 & 30 & 12 & 20 & 9 & 15 & 16 & 26.7 \\
High (3) & 25 & 41.7 & 10 & 16.7 & 12 & 20 & 10 & 16.7 \\
Extreme (4) & 7 & 11.7 & 6 & 10 & 8 & 13.3 & 8 & 13.3 \\
\hline
\end{tabular}

Table 3. Correlations between the personal and disease characteristics, and participation measures (RAL, by the ACS; performance and satisfaction, by the COPM $(\mathrm{N}=60)$.

\begin{tabular}{cccc}
\hline \multirow{2}{*}{$\begin{array}{c}\text { Personal and Disease } \\
\text { Characteristics }\end{array}$} & \multicolumn{2}{c}{ Participation Measures } \\
\cline { 2 - 4 } Stage of Cancer & Total Retained Activity Level (RAL) & Total Level of Performance & Total Level of Satisfaction \\
Surgery & NS & $-0.30^{*}$ & $-0.33^{* *}$ \\
Medical Treatment & NS & NS & NS \\
Age & NS & NS & NS \\
Educational Attainment Level & $0.24^{*}$ & NS & NS \\
Marital Status & $0.40^{* *}$ & NS & $-0.31^{*}$ \\
Monthly Income & NS & $-0.25^{*}$ & NS \\
Physical & $0.34^{* *}$ & NS & $-0.23^{*}$ \\
Cognitive & $-0.43^{* *}$ & $-0.25^{*}$ & NS \\
LROM & $-0.42^{* *}$ & NS & $-0.37^{* *}$ \\
Psychological & $-0.33^{* *}$ & $-0.39^{* *}$ & NS \\
\hline
\end{tabular}

${ }^{*} p<0.05 ;{ }^{* *} p \leq 0.01$

correlated with the RAL, however, all the symptoms examined correlated with the total RAL. Specifically, as the severity of symptoms increased, the total RAL significantly decreased. Women with a lower total RAL were more likely to be younger (under the age of 45 years) $(r=0.24, p=0.04)$, with a lower educational attainment level ( $\mathrm{r}=0.40, p=0.001)$, had a lower monthly income $(\mathrm{r}=0.34, p=0.001)$.

The symptoms and demographic variables that correlated with the total RAL were included in a multivariate regression analysis. The first regression step (Table 4) included all independent demographic variables that correlated with total RAL (age, level of education, and monthly income). This regression showed that age and education level explained $29 \%$ of total RAL $\left(\mathrm{R}^{2}=0.29\right.$, Adj. $\left.R^{2}=.22, F_{(5,54)}=4.32, p=0.00\right)$. Older women (over 45 years) $(\beta=0.25, p<0.05)$ and women with higher levels of education $(\beta=0.25, p=0.05)$ retained higher total activity levels following treatment for BC.

The second regression step included all the research variables found to be related to total RAL (time since diagnosis, LROM, psychological, physical and cognitive symptoms), and showed that these variables explained $51 \%$ of the variance in the total RAL $\left(\mathrm{R}^{2}=0.51\right.$, Adj. $\left.R^{2}=0.38, F_{(12,47)}=4.04, p=0.01\right)$. The variable that made the largest contribution toward explaining the total RAL was $\operatorname{LROM}(\beta=-0.30, p<0.05$, indicating that women with more severe limited range of motion in the upper extremity retained lower total activity levels following treatment for BC.

In summary, the regression analysis demonstrated that total RAL was not explained by the disease variables, but by three other variables: LROM on the affected side, young age, and lower educational attainment level. 
Table 4. Hierarchical regression analysis of the independent variables that explained the total level of participation.

\begin{tabular}{|c|c|c|c|c|c|c|}
\hline \multirow{2}{*}{ Variable } & \multicolumn{3}{|c|}{ Regression Step 1 Demographic Variables } & \multicolumn{3}{|c|}{ Regression Step 2 All Variables } \\
\hline & B & SEB & $\beta$ & B & SEB & $\beta$ \\
\hline Age & 0.10 & 0.05 & $0.25^{*}$ & 0.09 & 0.05 & $0.22^{*}$ \\
\hline Educational Level $\dagger$ & 0.10 & 0.05 & $0.25^{*}$ & 0.08 & 0.05 & 0.20 \\
\hline Monthly Income $†$ & 0.08 & 0.05 & 0.20 & 0.06 & 0.05 & 0.14 \\
\hline Physical Symptoms & & & & -0.01 & 0.02 & -0.04 \\
\hline Time Since Diagnosis & & & & 0.00 & 0.00 & 0.20 \\
\hline LROM & & & & -0.04 & 0.02 & $-0.30^{*}$ \\
\hline Psychological Symptoms & & & & -0.02 & 0.02 & -0.16 \\
\hline Cognitive Symptoms & & & & -0.03 & 0.02 & -0.23 \\
\hline $\mathrm{R}^{2}$ & & 0.29 & & & 0.51 & \\
\hline Change $\mathrm{F}$ & & $4.32^{* * *}$ & & & $4.04^{* *}$ & \\
\hline
\end{tabular}

${ }^{\dagger}$ Dummy variables: Age $\left(1=\right.$ age $>45$ years); Monthly income $\left(1=\right.$ high). ${ }^{*}$ Significant at $p<0.05 ;{ }^{* *}$ significant at $p<0.01 ;{ }^{* * *}$ significant at $p<0.001$. Variables with $p<0.05$ were found not significant (NS) and $p$-values were omitted.

\subsection{Variables Correlated with Performance and Satisfaction from Prioritized Activities}

The descriptive statistics collected from the COPM regarding the five daily activities receiving the highest importance scores showed that the most commonly preferred activities were work (33\% of the women), housekeeping (27\%), shopping (20\%), self-care (11\%), and social/leisure activity (9\%).

Correlations between the average performance and satisfaction scores (from the COPM) and the independent variables (Table 3) reveal that significantly lower scores for performance and satisfaction correlate with greater severity of LROM and with greater severity of physical symptoms. Thus, women with more severe LROM and physical symptoms reported lower performance levels and were less satisfied with their performance.

\subsection{Factors Correlating with RAL at Work Following Treatment for BC}

The majority of women (67\%) reported that they decreased their weekly working hours following commencement of medical treatments. At the time of data collection, eleven women (18.4\%) reported not returning to work (two were dismissed, one decided to leave and the rest 8 were uncertain about their employment future). This finding is in line with the responses to the "work" item added to the ACS (modified) tool, which showed a significantly decreased RAL at work, as found by Wilcoxon ( $\mathrm{Z}=-5.39, p<0.01, \mathrm{n}=60)$. Although they had a decreased RAL at work, women in this study returned to work within an average of six months ( $6 \pm 2$ months) after commencing treatment. It is tempting to consider that the decreased RAL for work may be a consequence of the rapid return to work, however, women who returned earlier to work actually had a higher RAL at work ( $\mathrm{r}$ $=-0.42, p<0.01$ ).

In addition, higher RAL at work was found among women with higher educational attainment level $(\mathrm{r}=0.23$, $p<0.05, \mathrm{~N}=60)$; among women with higher monthly incomes $(\mathrm{r}=0.30, p<0.05, \mathrm{~N}=60)$; and for women with less severe cognitive symptoms (Spearman's rs $=-0.32, p<0.05, \mathrm{~N}=60$ ). No other correlations were found between RAL at work and demographic and disease variables.

\subsection{Factors That Facilitated or Impeded Return to Work}

In order to understand decreased participation at work (as measured by RAL) better and to derive principles for OT rehabilitation, the content of the two open-ended questions (which examined factors facilitating or impeding return to work) was analyzed.

1) Personal and disease factors: $20 \%$ of the women reported that they returned to work in order to distract themselves from thinking about BC, and $18 \%$ wanted to feel a sense of normalization. In contrast, among 
$25 \%$ of the women, the decision to quit their job was made out of a stated need to achieve balance and promote meaning in their family life.

For many women (45\%), disease factors and symptoms following treatments were also reported as factors that impeded return to work. Symptoms such as LROM and lymphedema in the hand, fatigue, sleepiness, and cognitive deficits were mentioned as impeding return to work, as were a decline in the immune system and the risk of being in contact with people.

2) Factors related to job demands: $37 \%$ of the women mentioned that having flexible working hours and a job whose sick leave covered medical treatments facilitated return to work. In contrast, $40 \%$ of the women reported the presence of impeding job factors, such as high physical and cognitive demands.

3) Factors related to human and physical work environments: $46 \%$ of the women reported various environmental factors as facilitating an earlier return to work. Such factors included those pertaining to the human environment, such as support from the employer and colleagues, and employer understanding of the women's needs as they coped with the disease. Women whose work was located far from their place of residence $(15 \%)$ preferred to delay their return to work because of the difficulty in driving or using public transportation, for long time. In contrast, for $10 \%$ of the women, the ability to work from home facilitated their return to work or even enabled them to working during treatment.

\section{Discussion}

Our finding of considerably decreased RAL among women who have commenced treatment for BC provides quantitative evidence that BC treatment severely affects women's ability to retain previous activity levels in their home, work and leisure environments. However, current rehabilitation methods tend not to focus on women's occupational functioning [10]. Our quantitative finding thus exposes a profound deficit between rehabilitation needs and methods that can only be overcome through raising awareness, training of teams and focussed research.

With respect to the first objective of this study, total RAL could not be explained directly by any disease measure, but was explained by LROM of the upper extremity, age and education. For researchers, this finding indicates the complex explanation of participation and functioning, which do not depend solely on the disease, but are multi-casual, as described in the ICF framework [9], yet our study limited its scope, leaving the ICF environmental factors for future studies. For clinicians, the strong contribution of the limited range of motion in the upper extremity to women's retained activity level and its negative correlation with women's satisfaction and performance in their daily activities emphasize the importance of the early detection and treatment of upper extremity functioning [38]. General practitioners can play an important role here by raising the matter with patients and referring them to physical and occupational therapy, especially among young women with lower level of education, identified at risk.

With respect to the second objective of the study, which utilized a client-centered assessment, the activity prioritized by the largest percentage of women was work. Our study provides specific evidence in support of a recent call to develop return-to-work interventions [39]. Furthermore, more women prioritized productive activities (such as work, housekeeping, and shopping) than prioritized self-care and social activities. This finding can inform the prioritizations necessarily made by the medical and rehabilitation teams, as they plan survivorship care for BC survivors.

With respect to the third objective of this study, integrating the information from both tools (ACS and COPM) revealed impaired performance in women's productive activities (including work) and reduced RAL at work. Nevertheless, the average time until returning to work was found to be slightly shorter compared with other studies [22] [23] [40], perhaps due the economic pressure to support a family by two salaries and the social norms for productivity. Both tools also showed that cognitive symptoms correlated with reduced RAL at work (ACS) and with performance scores in the productive activities (COPM), similarly to findings by [41]. These findings call upon rehabilitation teams to address the decreases in attention, memory, and executive functions to enable women to manage the health situations and therapies integrated in their daily activities in order to facilitate early return to work among BC survivors [23].

The strongest facilitators of return to work that the women identified were flexible working hours and a supportive employer and colleagues. The women identified two main impediments to returning to work-disease factors, and high physical and cognitive demands. These factors are tightly linked, in that disease factors may 
affect a woman's ability to fulfil physically or cognitively demanding functions. Furthermore, in assessing BC patients, rehabilitation teams should take into account that women may regard work itself as either a benefit or a burden: for about a quarter of the women, working provides distraction or a sense of normalization, however about a fifth of the women left employment to look for new meaning and to achieve better life balance. The facilitators and barriers identified here are broadly in line with those found in a review by [23]. Our identification of these factors may contribute to the understanding of and development of rehabilitation interventions that enhance women's participation at work following treatment for BC, as suggested by [13].

\subsection{Limitations}

It should be noted that this study relied on self-reports rather than obtaining objective measures of upper extremity biomechanics, such as strength, pain, and sensation, and of cognitive limitations, such as memory and executive functioning. Its primary outcome measure, RAL, calculates the score for participation level categorically (for example "do less") in the activities ever performed by the women (out of 89), as perceived by participants. The ACS does not measure how much time is spent on each activity. Hence, results may overstate participation levels, which should be explored in future studies using additional measures. Finally, back-to-work experiences (facilitators and impediments) were explored using two open ended questions rather than via qualitative interviews. Further studies should be undertaken in other countries to confirm the generalizability of our findings. Such studies should combine self-reports with observations and quantitative assessments. A longitudinal study would be helpful in investigating participation throughout long-term BC survival, including pre-post intervention.

\subsection{Implications and Recommendations}

The current study focused on a neglected area of the perceptions of women with BC concerning their needs and priorities with respect to functioning and participation. It quantifies the severe effect of breast cancer treatment on occupational functioning and calls to raise awareness to the long term BC treatment-related deficits in all areas of physical, cognitive, and emotional functioning.

All stakeholders should consider the reported fatigue and the weakened immune system effecting survivors' reluctance to go to crowded places, such as public transportation and workplaces. Findings make general practitioners aware of the variables that most influence the ability of BC survivors to retain their former levels of activity (namely, LROM, young age, and lower education) and which activities are of most importance to them (productive activities, particularly work). Findings also imply that general practitioners, as those primarily tasked with survivorship care, should raise with their patients the issue of their daily routines, supported by evidence based rehabilitation interventions aiming to improve their participation and well-being. Such interventions might require training of rehabilitation teams to focus on range of motion, executive functions, and management of daily activities. Following the barriers women reported in the current study, occupational therapists may facilitate their return-to-work by analysing the job demands and looking for applicable reasonable accommodations.

Despite the limitations mentioned, a key methodological strength of the study is that the quantitative portion was adequately powered and therefore cautious generalizations may be made. An additional strength is that the study integrated data from several tools. Using the combined tools provided the advantage of enabling us to acquire complimentary data gathered from two different frameworks. Such an integrative understanding enables clinicians to focus on health promotion strategies and to provide women with the knowledge and skills needed to manage their condition [10], in order to obtain better health outcomes [42].

In light with these recommendations, the authors are currently designing and examining a pilot intervention that will combine in-person sessions together with on-line sessions, aiming to address women's identified functional needs and priorities. Such interventions may help women to self-manage their daily functioning, return to work, cope with the disease, and comply with the treatments.

\section{Acknowledgements}

This work was supported by the Israel Cancer Association Grant 20120072-C.

The authors cordially thank the women who participated for their time, effort, and willingness to share their experiences. 


\section{Conflict of Interest}

The authors report no conflicts of interest. The authors alone are responsible for the content and writing of the paper.

\section{References}

[1] Bakitas, M.A. (2007) Background Noise: The Experience of Chemotherapy-Induced Peripheral Neuropathy. Nursing Research, 56, 323-331. http://dx.doi.org/10.1097/01.NNR.0000289503.22414.79

[2] Chopra, I. and Kamal, K.M. (2012) A Systematic Review of Quality of Life Instruments in Long-Term Breast Cancer Survivors. Health and Quality of Life Outcomes, 10, 14. http://www.hqlo.com/content/10/1/14

[3] Loh, S., Packer, T., Chinna, K. and Quek, K. (2013) Effectiveness of a Patient Self-Management Programme for Breast Cancer as a Chronic Illness: A Non-Randomised Controlled Clinical Trial. Journal of Cancer Survivorship, 7, 331342. http://dx.doi.org/10.1007/s11764-013-0274-X

[4] Egan, M.Y., McEwen, S., Sikora, L., Chasen, M., Fitch, M. and Eldred, S. (2013) Rehabilitation Following Cancer Treatment. Disability and Rehabilitation, 35, 2245-2258. http://dx.doi.org/10.3109/09638288.2013.774441

[5] Selamat, M., Loh, S., Mackenzie, L. and Vardy, J. (2014) Chemobrain Experienced by Breast Cancer Survivors: A Meta-Ethnography Study Investigating Research and Care Implications. PLoS ONE, 9, e108002.

[6] American Cancer Society 2014 Cancer Facts and Figures. http://www.cancer.org/research/cancerfactsstatistics/cancerfactsfigures2014

[7] Désiron, H.A., Donceel, P., De-Rijk, A. and Van Hoof, E. (2013) A Conceptual-Practice Model for Occupational Therapy to Facilitate Return to Work in Breast Cancer Patients. Journal of Occupational Rehabilitation, 23, 516-526. http://dx.doi.org/10.1007/s10926-013-9427-z

[8] Lyons, K.D., Hull, J.G., Kaufman, P.A., Li, Z., Seville, J.L., Ahles, T.A., Kornblith, A.B. and Hegel, M.T. (2015) Development and Initial Evaluation of a Telephone-Delivered, Behavioral Activation, and Problem-Solving Treatment Program to Address Functional Goals of Breast Cancer Survivors. Journal of Psychosocial Oncology, 33, 199-218. http://dx.doi.org/10.1080/07347332.2014.1002659

[9] World Health Organization (2001) International Classification of Functioning, Disability and Health. World Health Organization, Geneva.

[10] Loh, S. and Musa, A. (2015) Methods to Improve Rehabilitation of Patients Following Breast Cancer Surgery: A Review of Systematic Reviews. Breast Cancer: Targets and Therapy, 7, 81-98. http://dx.doi.org/10.2147/bctt.s47012

[11] Heins, M.J., Korevaar, J.C., Rijken, P.M. and Schellevis, F.G. (2013) For Which Health Problems Do Cancer Survivors Visit Their General Practitioner? European Journal of Cancer, 49, 211-218. http://dx.doi.org/10.1016/j.ejca.2012.07.011

[12] Lattanzi, J.B., Giuliano, S., Meehan, C., Sander, B., Wootten, R. and Zimmerman, A. (2010) Recommendations for Physical and Occupational Therapy Practice from the Perspective of Clients Undergoing Therapy for Breast Cancer-Related Impairments. Journal of Allied Health, 39, 257-264.

[13] Désiron, H.A., Crutzen, R., Godderis, L., Hoof, E. and Rijk, A. (2016) Bridging Health Care and the Workplace: Formulation of a Return-to-Work Intervention for Breast Cancer Patients Using an Intervention Mapping Approach. Journal of Occupational Rehabilitation, 1-16. http://dx.doi.org/10.1007/s10926-015-9620-3

[14] McColl, M.A. and Pollock, N. (2000) Measuring Occupational Performance Using a Client-Centered Perspective. In: Law, M., Baum, C. and Dunn, W., Measuring Occupational Performance: Supporting Best Practice in Occupational Therapy, SLACK Incorporated, USA, 65-76.

[15] Vrkljan, B. and Miller-Polgar, J. (2001) Meaning of Occupational Engagement in Life-Threatening Illness: A Qualitative Pilot Project. Canadian Journal of Occupational Therapy, 68, 237-246. http://dx.doi.org/10.1177/000841740106800407

[16] Singletary, S.E. and Connolly, J.L. (2006) Breast Cancer Staging: Working with the Sixth Edition of the AJCC Cancer Staging Manual. CA: A Cancer Journal for Clinicians, 56, 37-47. http://dx.doi.org/10.3322/canjclin.56.1.37

[17] Anampa, J., Makower, D. and Sparano, J.A. (2015) Progress in Adjuvant Chemotherapy for Breast Cancer: An Overview. BMC Medicine, 13, 195. http://dx.doi.org/10.1186/s12916-015-0439-8

[18] Ness, K.K., Wall, M.M., Oakes, J.M., Robison, L.L. and Gurney, J.G. (2006) Physical Performance Limitations and Participation Restrictions among Cancer Survivors: A Population-Based Study. Annals of Epidemiology, 16, 197-205. http://dx.doi.org/10.1016/j.annepidem.2005.01.009

[19] Balak, F., Roelen, C.A., Koopmans, P.C., Elike, E. and Groothoff, J.W. (2008) Return to Work after Early-Stage Breast Cancer: A Cohort Study into the Effects of Treatment and Cancer-Related Symptoms. Journal of Occupational Rehabilitation, 18, 267-272. http://dx.doi.org/10.1007/s10926-008-9146-z 
[20] Tiedtke, C., De Rijk, A., Donceel, P., Christiaens, M. and de Casterlé, B.D. (2012) Survived but Feeling Vulnerable and Insecure: A Qualitative Study of the Mental Preparation for RTW after Breast Cancer Treatment. BMC Public Health, 12, 538. http://dx.doi.org/10.1186/1471-2458-12-538

[21] Sanchez, K.M., Richardson, J.L. and Mason, H.R. (2004) The Return to Work Experiences of Colorectal Cancer Survivors. AAOHN Journal: Official Journal of the American Association of Occupational Health Nurses, 52, 500-510.

[22] Tiedtke, C., De Rijk, A., De Casterlé, B.D., Christiaens, M. and Donceel, P. (2010) Experiences and Concerns about "Returning to Work" for Women Breast Cancer Survivors: A Literature Review. Psycho-Oncology, 19, 677-683. http://dx.doi.org/10.1002/pon.1633

[23] Islam, T., Dahlui, M., Majid, H.A., Nahar, A.M., Taib, N.A. and Su, T.T. (2014) Factors Associated with Return to Work of Breast Cancer Survivors: A Systematic Review. BMC Public Health, 14, S8. http://dx.doi.org/10.1186/1471-2458-14-s3-s8

[24] Pennisi, M., Chisari, G., Vacante, M., et al. (2013) The Role of Work in Breast Cancer Patients. Journal of Cancer Therapy, 4, 1330.

[25] American Occupational Therapy Association (2002) Occupational Therapy Practice Framework: Domain \& Process. The American Journal of Occupational Therapy, 56, 609-639. http://dx.doi.org/10.5014/ajot.56.6.609

[26] Eakman, A.M. and Eklund, M. (2012) The Relative Impact of Personality Traits, Meaningful Occupation and Occupational Value on Meaning in Life and Life Satisfaction. Journal of Occupational Science, 19, 165-177. http://dx.doi.org/10.1080/14427591.2012.671762

[27] Schmitz, K.H., Stout, N.L., Andrews, K., Binkley, J.M. and Smith, R.A. (2012) Prospective Evaluation of Physical Rehabilitation Needs in Breast Cancer Survivors. Cancer, 118, 2187-2190. http://dx.doi.org/10.1002/cncr.27471

[28] Faul, F., Erdfelder, E., Buchner, A. and Lang, A.G. (2009) Statistical Power Analyses Using G*Power 3.1: Tests for Correlation and Regression Analyses. Behavior Research Methods, 41, 1149-1160. http://dx.doi.org/10.3758/BRM.41.4.1149

[29] Hartman-Maeir, A., Soroker, N., Ring, H., Avni, N. and Katz, N. (2007) Activities, Participation and Satisfaction One-Year Post Stroke. Disability and Rehabilitation, 29, 559-566. http://dx.doi.org/10.1080/09638280600924996

[30] Cella, D.F., Tulsky, D.S., Gray, G., Sarafian, B., Linn, E., Bonomi, A. and Brannon, J. (1993) The Functional Assessment of Cancer Therapy Scale: Development and Validation of the General Measure. Journal of Clinical Oncology, 11, 570-579.

[31] Baum, C.M., Edwards, D. and Michael, E. (2001) Activity Card Sort (ACS) (Translated to Hebrew by Katz, N. and Hertman-Meier). Washington University School of Medicine, St. Louis.

[32] Katz, N. and Hartman-Maeir, A. (2001) Activity Card Sort: Israeli Version. Hebrew University, Graduate Program in Occupational Therapy, Jerusalem.

[33] Katz, N., Karpin, H., Lak, A., Furman, T. and Hartman-Maeir, A. (2003) Participation in Occupational Performance: Reliability and Validity of the Activity Card Sort. OTJR: Occupation, Participation and Health, 23, 10-17.

[34] Sachs, D. and Josman, N. (2003) The Activity Card Sort: A Factor Analysis. OTJR: Occupation, Participation and Health, 23, 165-174.

[35] Law, M., Baptiste, S., McColl, M., Opzoomer, A., Polatajko, H. and Pollock, N. (1990) The Canadian Occupational Performance Measure: An Outcome Measure for Occupational Therapy. Canadian Journal of Occupational Therapy, 57, 82-87. http://dx.doi.org/10.1177/000841749005700207

[36] McColl, M.A., Paterson, A., Davies, D., Doubt, L. and Law, M. (2000) Validity and Community Utility of the Canadian Occupational Performance Measure. Canadian Journal of Occupational Therapy, 67, 22-30. http://dx.doi.org/10.1177/000841740006700105

[37] IBM Corp. (2010) IBM SPSS Statistics for Windows, Version 19.0. IBM Corp., Armonk.

[38] Stout, N.L., Binkley, J.M., Schmitz, K.H., Andrews, K., Hayes, S.C., Campbell, K.L. and Cheville, A.L. (2012) A Prospective Surveillance Model for Rehabilitation for Women with Breast Cancer. Cancer, 118, 2191-2200. http://dx.doi.org/10.1002/cncr.27476

[39] Désiron, H.A., Donceel, P., Godderis, L., Van Hoof, E. and Rijk, A.D. (2015) What Is the Value of Occupational Therapy in Return to Work for Breast Cancer Patients? A Qualitative Inquiry among Experts. European Journal of Cancer Care, 24, 267-280. http://dx.doi.org/10.1111/ecc.12209

[40] Fantoni, S.Q., Peugniez, C., Duhamrael, A., Skrzypczak, J., Frimat, P. and Leroyer, A. (2010) Factors Related to Return to Work by Women with Breast Cancer in Northern France. Journal of Occupational Rehabilitation, 20, 49-58. http://dx.doi.org/10.1007/s10926-009-9215-y

[41] Cheung, Y.T., Shwe, M., Tan, Y.P., Fan, G., Ng, R. and Chan, A. (2012) Cognitive Changes in Multiethnic Asian Breast Cancer Patients: A Focus Group Study. Annals of Oncology: Official Journal of the European Society for Medical Oncology ESMO, 23, 2547-2552. http://dx.doi.org/10.1093/annonc/mds029 
[42] Mosen, D.M., Schmittdiel, J., Hibbard, J., Sobel, D., Remmers, C. and Bellows, J. (2007) Is Patient Activation Associated with Outcomes of Care for Adults with Chronic Conditions? The Journal of Ambulatory Care Management, $\mathbf{3 0}$, 21-29. http://dx.doi.org/10.1097/00004479-200701000-00005

\section{Submit or recommend next manuscript to SCIRP and we will provide best service for you:}

Accepting pre-submission inquiries through Email, Facebook, LinkedIn, Twitter, etc. A wide selection of journals (inclusive of 9 subjects, more than 200 journals)

Providing 24-hour high-quality service

User-friendly online submission system

Fair and swift peer-review system

Efficient typesetting and proofreading procedure

Display of the result of downloads and visits, as well as the number of cited articles

Maximum dissemination of your research work

Submit your manuscript at: http://papersubmission.scirp.org/ 